\title{
Adana ilinde sulama açısından kuraklık analizi
}

\section{Drought analysis for Adana province in terms of irrigation scheduling}

\author{
Mete ÖZFIDANER , Engin GÖNEN(®) \\ Alata Bahçe Kültürleri Araştırma Enstitüsü Müdürlüğü, Mersin \\ Sorumlu yazar (Corresponding author): M. Özfidaner, e-posta (e-mail): mete.ozfidaner@tarimorman.gov.tr \\ Yazar(lar) e-posta (Author e-mail): engin.gonen@tarimorman.gov.tr
}

\section{MAKALE BİLGİSİ}

Alınış tarihi 30 Temmuz 2020

Düzeltilme tarihi 30 Eylül 2020

Kabul tarihi 12 Ekim 2020

\section{Anahtar Kelimeler:}

Güvenilir yağış

RAINBOW

Adana

Yağış analizi

\begin{abstract}
ÖZ
Son yıllarda özellikle sulama açısından iklim değişikliğine bağlı yağışlarla birlikte ortaya çıkan kuraklık Adana'da önemli sorunları ortaya çıkarmıştır. Bu sorunların başında ise en uygun sulama zamanının programlanması gelmektedir. En uygun sulama zaman programının oluşturulması için güvenilir yağış değerlerinin bilinmesi gerekmektedir. Güvenilir yağış belirli olasılıkla oluşması beklenen yağışı ifade etmektedir. Yağışlı, normal ve kurak dönemlerde beklenen güvenilir yağış değerleri yağış analizleri ile belirlenmektedir. Bu çalışmada Adana meteoroloji istasyonundan 1960-2018 yılları arası gözlenen aylık, mevsimlik ve yılllı yağıș değerleri RAINBOW bilgisayar yazılımı ile analiz edilmiştir. Adana'da yağışılı bir yılda 804.8 mm ve üzeri yağış beklenirken, kurak yıllarda $492.6 \mathrm{~mm}$ ve altında yağış beklenmektedir. Ayrıca kıș aylarında, kurak yıllarda $196.7 \mathrm{~mm}$, İlkbaharda 107.6, sonbaharda $67.6 \mathrm{~mm}$ ve yaz mevsiminde $7.2 \mathrm{~mm}$ ve altında yağış olması durumunda kuraklık belirlenmiştir.
\end{abstract}

\section{ARTICLE INFO}

Received 30 July 2020

Received in revised form 30 September 2020

Accepted 12 October 2020

\section{Keywords:}

Reliable rainfall

RAINBOW

Adana

Precipitation analysis

\begin{abstract}
In recent years, the drought that has emerged with the precipitation due to change in climate especially in terms of irrigation has revealed important problems in Adana. One of these problems is programming the most suitable irrigation time. Irrigation program for creating the most appropriate time to know the value is reliable rainfall. Reliable rainfall expected to occur with certain probability of precipitation is expressed. Wet, normal and dry during periods of expected rainfall for reliable rainfall is determined by analysis. In this study, monthly, seasonal and annual precipitation values observed from Adana meteorology station between 1960-2018 were analyzed with RAINBOW software. While $804.8 \mathrm{~mm}$ and above precipitation is expected in Adana in a rainy year, $492.6 \mathrm{~mm}$ and below precipitation is expected in dry years. In addition, drought was determined in case of precipitation in winter, $196.7 \mathrm{~mm}$ in winter, $107.6 \mathrm{~mm}$ in spring, $67.6 \mathrm{~mm}$ in autumn and $7.2 \mathrm{~mm}$ or less in summer.
\end{abstract}

\section{Giriş}

Atmosferden katı veya sıvı halde yeryüzüne düşen sulara yağış denir. Yağışlar, mekan ve zaman içinde, su dengesindeki değişkenliğin belli başlı kaynağıdır. Yağışların yersel ve zamansal dağılım bakımından farklılı̆̆ını ortaya koyabilmek için belirli zaman aralıklarında ölçümlerinin yapılması zorunludur. Değişik zaman aralıklarında ölçülen yağış miktarları genellikle haftalık, on günlük, aylık ve yıllık toplam olarak ifade edilir. Yağışlarda meydana gelen değişimler, hidroloji ve su kaynakları için çok önemli sonuçlar doğurabilir. Ülkemizde, sulama sistemlerinin kapasiteleri belirlenirken uzun yıllık ortalama yağış değerleri kullanılmaktadır. Uzun yıllık ortalama yağı̧̧ değerlerinin kullanılması bazı sıkıntılara yol açmaktadır. $\mathrm{Bu}$ sorunlardan bir tanesi kurak yıllarda sulama sistemlerinin kapasitesinin yetersiz kalmasıyla birlikte, sulanacak alanının tamamının sulanmasını engellemekte ve kısıntılı sulama uygulamasına yol açmaktadır. $\mathrm{Bu}$ durum sulu tarım alanında elde edilen gelirin azalmasına neden olmaktadır. Ortaya çıkan sorunları çözmek üzere birçok ülkede sulama sistemlerinin kapasitelerinin belirlenmesinde ve işletilmesinde kurak yılda beklenen güvenilir yağış değerlerinin kullanılması önerilmektedir (Yıldırım 2002).

Yağış frekans analizleri ile kurak, normal ve yağışlı herhangi bir dönemde (yıl, ay, on gün v.b.) beklenen yağış miktarları belirlenebilmekte, bu değerlere güvenilir yağış adı verilmektedir. $\mathrm{Bu}$ analizler geçmiş y1llarda herhangi bir dönemde ölçülen yağış değerleri kullanılarak istatistiksel olarak farklı olasılık düzeyleri için yapılmaktadır. Sulama ile ilgili çalışmalarda, herhangi bir kurak dönemde beklenen güvenilir yağış miktarı belirlenirken $\% 80$, yağışı güvenilir yağış miktarı belirlenirken $\% 20$ olasıllı düzeyi kullanılmaktadır (Mengü ve ark. 2007). Sulama projeleri için 
önerilen değer \%80 olasılıkla düşmesi beklenen yağıştır. Sulama amaçlı güvenilir yağış analizinde en az 15 yıllık gözlem dönemine sahip yağış verilerinin kullanılması gerekmektedir (Smith 1992).

Bir yöreye düşen güvenilir yağış değerlerinin bilinmesi; düşen yağıştan sulamada optimum düzeyde yararlanılacak biçimde sulama zaman planlamasının yapılmasını sağlar. Buna bağlı olarak ta bilinçsizce yapılan sulamalar ile bölgede taban suyu düzeyinin artması ve tarım alanlarının bu durumdan zarar görmesinin engellenebilir (Haque 2005). Kurak yıl yağış değerleri maksimum şebeke su ihtiyacının belirlenmesinde; normal yıl yağış değerleri sulama şebekelerinin göstergelerinin, rezervuar işletme planlarının geliştirilmesinde ve sulama zamanının planlanmasında; yağışlı yıl yağış değerleri ise sulamanın her zaman gerekli olup olmadığının belirlenmesinde kullanılmaktadır (Kodal ve ark. 2003).

$\mathrm{Bu}$ çalışmada tarımsal açıdan önemli bir konuma sahip Adana ilinin sulama açısından kuraklık analizi yapılarak kurak, yağışlı ve normal yıllarda ve aylarda düşmesi beklenen güvenilir yağış değerlerinin belirlenmesi hedeflenmiştir.

\section{Materyal ve Yöntem}

\subsection{Materyal}

Araştırma alanı olarak seçilen Adana ili, Türkiye'nin güneyinde Seyhan Havzasında yer almaktadır. Çalışmada çarpık kentleşmenin ve tarımın yoğun olduğu bir alanda kurulmuş bulunan Adana Meteoroloji istasyonunda 1960-2018 y1lları arasında ölçülen aylık toplam yağış değerleri kullanılmıştır.

\subsection{Yöntem}

Gözlenen yıllık ve aylık yağış değerlerinin analizinde RAINBOW bilgisayar yazılımı kullanılabilmektedir. Bu yazılım ile zaman serilerinin homojenlik testi ve olasılık dağılım analizleri farklı yaklaşımlarla yapılabilmektedir. Farklı olasılıklar için elde edilen güvenilir yağış değerleri çizelge veya grafik şeklinde ifade edilmektedir (Raes ve ark. 1989; Raes ve ark. 2006). Yazılım ile yağış analizi yapılabilmesi için izlenen aşamalar Raes ve ark. (2006), tarafindan aşağıdaki şekilde tanımlanmaktadir:

- Analiz edilecek uzun yıllara ilişkin aylık veya on günlük veriler ayrı dosyalara girilerek veri değişim aralığı ve zaman serisi ayarlanmaktadır.

- Değerlerden herhangi biri diğerlerinden çok fazla büyükse, bu değer değerlendirme dışı bırakılabilmektedir.

- Çalışmanın amacına göre bütün yağış değerleri değerlendirmeye alınabilmekte (yani sınır sıfır alınabilir), ya da belli bir sınırdan büyük olan yağışlar (örneğin $1 \mathrm{~mm}$ 'den büyük yağışlar) değerlendirmeye alınabilmektedir. Çizelge ve grafik sonuçlarına göre $\% 90,95$ ve 99 olasılık düzeyleri için verilerin homojen olup olmadığına bakılmakta, eğer veriler homojen ise işleme devam edilmektedir. Homojenlik sağlanmıyorsa en büyük sapma gösteren yıldan önceki ve sonraki zaman dilimleri için ayrı ayrı işlem yapılmaktadır.

- Noktalama yönteminin seçimi: Yazılımda California, Hazen, Weibull ve Gringorten yöntemleri yer almaktadır.

- Dağılım türünün seçimi: Yazılımda Gumbel ve Normal dağılımlar yer almaktadır. Normal dağılım için doğrusal ve logaritmiksel dönüştürmeler ile moment ve olasılık ağırlıklı momentler yöntemi gibi parametre tahmin seçenekleri bulunmaktadır.

- Uygun çözümün belirlenmesi: Farklı noktalama ve dağılım türleri için olasılık grafikleri karşılaştırılarak, doğruya en yakın çıkan olasılık grafiği en uygun çözüm olarak alınmaktadır.

- Sonuçların alınması: Kabul edilen çözüme ilişkin olasılık tablosundan farklı olasılıkları (örneğin \%20, \%50 ve \%80) için beklenen güvenilir yağış değerleri alınmaktadır.

- Sonuçların yorumlanması: Farklı dönemler ve olasılıklar için belirlenen sonuçlar çizelge ve şekillerle yorumlanmaktadır. Yıllık yağış değerlerinin analizi ile yağış1 $(\% 20)$, normal (\%50) ve kurak (\%80) yıllarda oluşması beklenen güvenilir yağış değerleri belirlenebilmektedir.

\section{Bulgular ve Tartışma}

Çalışmada Adana meteoroloji istasyonun 1960-2018 yılları arasında gözlenen aylık ve yıllık yağış verileri RAINBOW yazılımı kullanılarak analiz edilmiş, analizde Adana'nın yağış verilerine Weibull noktalama yöntemi ve Gumbel dağılımının uygun olduğu belirlenmiştir. Yapılan analizler sonucu meydana çıkan yağışlı, kurak ve normal yıllarda oluşması beklenen güvenilir yağış değerleri Çizelge 1 'de verilmiştir.

Çizelge 1. Adana ili uzun yıllık ve mevsimlik yağış (1960-2018) analizi sonuçları (mm).

Table 1. Adana province annual and seasonal rainfall (1960-2018) analysis results $(\mathrm{mm})$.

\begin{tabular}{|c|c|c|c|c|}
\hline \multirow[b]{2}{*}{ Veri } & \multirow{2}{*}{$\begin{array}{c}\text { Ortalama } \\
\text { Uzun Yıllık } \\
\text { Yağıș (mm) }\end{array}$} & \multicolumn{3}{|c|}{ Yıllık Güvenilir Yağıș (mm) } \\
\hline & & $\begin{array}{c}\text { Yağışlı Y1l } \\
(\% 20)\end{array}$ & $\begin{array}{c}\text { Normal Y1l } \\
(\% 50)\end{array}$ & $\begin{array}{c}\text { Kurak Y1l } \\
(\% 80)\end{array}$ \\
\hline Yıllık Yağış & 663.4 & 804.8 & 625.7 & 492.6 \\
\hline Kış & 326.5 & 440.3 & 300.5 & 196.7 \\
\hline İlkbahar & 169.3 & 223.3 & 156.9 & 107.6 \\
\hline Yaz & 32.7 & 52.4 & 27.2 & 7.2 \\
\hline Sonbahar & 134.9 & 193.9 & 121.4 & 67.6 \\
\hline
\end{tabular}

Aylık, yıllık ve mevsimlik yağış değerlerinin analizi sonucunda yağışlı, kurak ve normal yıllar için belirlenen güvenilir yağış değerleri kullanılarak 59 yıllık dönem yağışl, normal ve kurak yıl olarak sınıflandırılmıştır. Uzun yıllık aylık ortalama yagış verilerinin analizi sonucunda ortaya çıkan yağışlı, kurak ve normal ay ile uzun yıllık aylık ortalama yağış değerleri Şekil 1'de grafiklenmiştir. Adana ilinde kurak geçmesi beklenen ocak ayında 38.4. $\mathrm{mm}$ ve altında yağış beklenirken, yağışlı geçmesi beklenen aynı ayda $172.4 \mathrm{~mm}$ ve üstünde yağış beklenmektedir (Şekil 1). Yağışlı geçmesi beklenen aylardaki (\%20 olasılıklı) yağış değerleri ortalama yağışın çok üstünde kurak aylarda(\%80 olasılıklı) ise çok altında kalmaktadır. Aylık ortalama yağışın az olduğu ağustos ayı için yağışı durumunda $10.8 \mathrm{~mm}$ yağışın olacağı fakat kurak bir ay durumunda ise hiç yağış olmadığı belirlenmiştir (Çizelge 2). Kurak geçmesi beklenen temmuz-eylül aylarında yağışın olmadığı belirlenmiştir. Bu durumda sulama açısından önemli olarak belirtilen kurak aylardaki düşmesi beklenen yağış miktarlarının sulama plan ve projelerinin hesap edilmesinde dikkate alınmalıdır. Kodal ve ark. (1992), sulama modülü hesabında kurak yıl ve güvenilir yağış değerlerinin dikkate alınmasının gerektiğini belirtmişlerdir. 
Mevsimsel olarak incelediğimiz zaman kurak, yağışl1, normal ve ortalama değerleri Şekil 2'de verilmiştir. Kış mevsiminde yağışlı geçmesi beklenen durumda $440.3 \mathrm{~mm}$, kurak geçmesi beklenenen durumda ise $196.7 \mathrm{~mm}$ yağışın olacağı Çizelge 2'den görülmektedir. Sulamanın yapıldığ İlkbahar ve Yaz mevsiminde ise, yağışlı durumda sırası ile 223.4 ve $52.4 \mathrm{~mm}$, kurak olmas1 durumunda 107.6 ve $7.2 \mathrm{~mm}$ yağışın meydana gelebileceği belirlenmiştir. Mevsimlik ortalama yağış değereri ile normal geçmesi beklene mevsim arasındaki değerler birbirine yakın çıkmıştır (Şekil 2).

Uzun yıllık ortalama aylık yağış değerlerinin toplamı 663.4 mm olarak Çizelge 2'de belirlenmiştir. Çizelge 2'de kurak bir y1l için toplam yağış miktarının $492.6 \mathrm{~mm}$, yağışlı bir y1l için $804.8 \mathrm{~mm}$ ve normal bir yıl için de $625.7 \mathrm{~mm}$ olduğu hesaplanmıştır. $\mathrm{Bu}$ durumun Çizelge 1'de belirlenen y1llık güvenilir yağış değerlerinden farklı olduğu ve özellikle yağışlı ve kurak aylarda bu durumun belirgin olduğu görülmektedir. $\mathrm{Bu}$ durumda sulama programlaması yapılırken aylık toplam güvenilir yağış verilerini kullanmak yerine yıllık olarak hesaplanan güvenilir yağış verilerini kullanmak daha iyi sonuçlar verecektir. Analiz sonucunda kurak geçmesi beklenen yaz aylarında aylık yağış $10 \mathrm{~mm}$ civarında iken, kış aylarında aylık yağış $48 \mathrm{~mm}$ civarlarına kadar çıkmaktadır. Yağışlı geçmesi beklenen kış aylarında aylık yağış 204 mm kadar çıkar iken, yaz aylarında $100 \mathrm{~mm}$ kadar düşmektedir. Normal geçmesi beklenen aylık yağışlar ile ortalama aylık yağışlar birbirine yakın değerler almıştır.

Adana ilinde 1960-2018 yılları arasında aylık toplam yağıș değerleri analizi sonucu meydana gelen kurak, yağışlı ve normal ay durumları Çizelge 3'de verilmiştir. Çizelgeye göre 19062018 yıllar arasında ocak ayında 14 adet kurak, 12 adet yağışlı durumlar belirlenmiştir. Ocak ayında 1971-1973, 1990-1992 ve 2006-2008 yıllarında kuraklık tespit edilmiştir. Haziran ayını incelediğimiz zaman 26 adet kurak, 10 adet yağışlı ay belirlenmiştir. Özellikle 1974-1977, 1984-1986, 2000-2004 ve 2008-2010 yılları arasında kurak aylar meydana gelmiştir. Temmuz-eylül ayları boyunca kurak dönem belirlenmemiş olup yağışlı ay sayıları sıra ile 7.9 ve 10 olarak bulunmuştur.

Aylık güvenilir yağış analizlerine göre Adana Metroloji istasyonuna ait yıl içindeki yağışlı, kurak ve normal ay sayıları Çizelge 4'de verilmiştir. Yıllık yağış sınıfı "KURAK" olarak belirlenmiş bir yıl için yıllık toplam yağış miktarı, o yılın beklenen güvenilir yağış değeri olan $492.6 \mathrm{~mm}$ 'den daha az veya eşit olması gerekli iken, "YAĞIŞLI" olarak sınıflandırılan y1lda ise bu miktar $804.8 \mathrm{~mm}$ 'den fazla veya eşit olması gerekmektedir. Belirlenen uzun yıllık toplam güvenilir yağış verilerine göre 1960-2018 (59 y1l) y1lları arasında 14 yıl kurak (1960, 1970-1973, 1982, 1986, 1990, 1993, 1999. 2002, 2008, 2013, 2017), 14 yıl yağış $(1961,1963,1967,1968,1976,1981$, 1987, 1988, 1991, 1994, 2009, 2012, 2018) ve 31 y1 ise normal geçmiştir. Kurak y1l olarak belirlenen 14 yılda yıllık toplam yağış 316.8 ile $482.2 \mathrm{~mm}$ arasında gerçekleşmiş̧ir. Çizelge 4'ten de görülebileceği gibi yıllık toplam yağış miktarları bakımından en yağışlı yıl olan 1968 yılında 5 ayın yağışlı sadece 1 ayın kurak geçtiği, aynı şekilde 1976, 1981, 1994 ve 2012 yıllarında da benzer durumların olduğu belirlenmiştir. Yılık toplam yağış miktarlarına göre en kurak geçen yıl olan

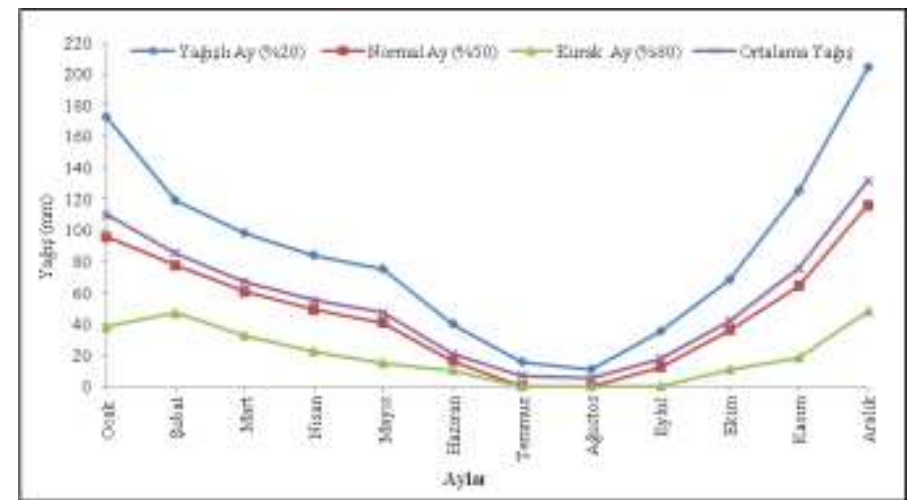

Şekil 1. Adana ili için aylık güvenilir yağış değerleri ve uzun yıllık aylık ortalaması.

Figure 1. Monthly reliable precipitation values and long annual monthly average for adana province.

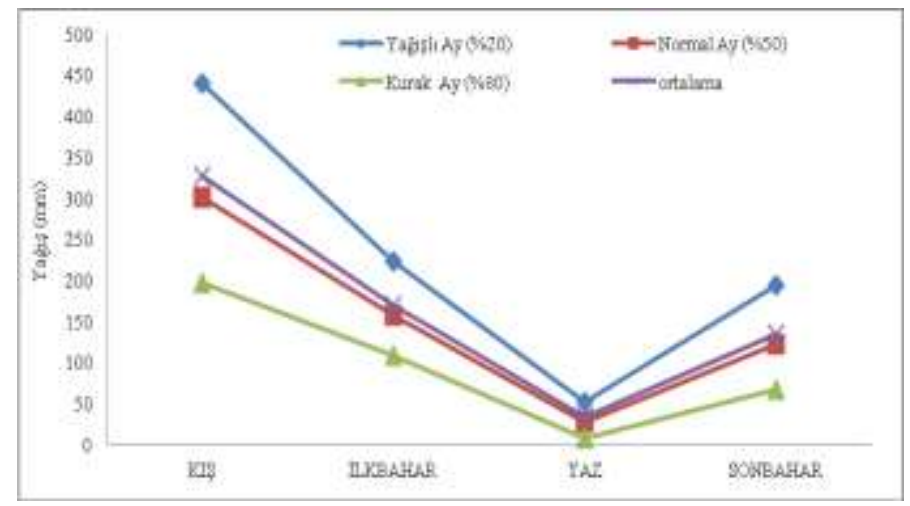

Şekil 2. Adana ili mevsimsel güvenilir yağış değerleri ve ortalama değerleri.

Figure 2. Seasonal reliable precipitation values and average values of adana province. 
Çizelge 2. Adana ili aylık, yıllık ve mevsimsel yağış analizi sonuçları.

Table 2. Monthly, annual and seasonal rainfall analysis results in Adana province.

\begin{tabular}{|c|c|c|c|c|}
\hline Aylar & $\begin{array}{c}\text { Yağışlı Ay } \\
(\% 20)\end{array}$ & $\begin{array}{c}\text { Normal Ay } \\
(\% 50)\end{array}$ & $\begin{array}{c}\text { Kurak Ay } \\
(\% 80)\end{array}$ & Ortalama Yağış \\
\hline Ocak & 172.4 & 95.6 & 38.4 & 109.8 \\
\hline Şubat & 119 & 77.4 & 46.9 & 85.3 \\
\hline Mart & 98 & 60.4 & 32.5 & 67.1 \\
\hline Nisan & 84 & 48.9 & 22.3 & 55.2 \\
\hline Mayıs & 74.9 & 40.6 & 15.1 & 47.0 \\
\hline Haziran & 39.8 & 16.3 & 10.1 & 20.6 \\
\hline Temmuz & 15.5 & 0 & 0 & 6.9 \\
\hline A ğustos & 10.8 & 0 & 0 & 5.2 \\
\hline Eylül & 35.1 & 12.1 & 0 & 17.7 \\
\hline Ekim & 68.3 & 35.9 & 11 & 41.8 \\
\hline Kasım & 124.9 & 64.2 & 18.3 & 75.4 \\
\hline Aralık & 204.1 & 115.8 & 47.9 & 131.3 \\
\hline Yıllık & 804.8 & 625.7 & 492.6 & 663.4 \\
\hline Kış & 440.3 & 300.5 & 196.7 & 326.5 \\
\hline İlkbahar & 223.3 & 156.9 & 107.6 & 169.3 \\
\hline Yaz & 52.4 & 27.2 & 7.2 & 32.7 \\
\hline
\end{tabular}

2008 yılında ise 4 ay kurak geçmiş diğer aylar normal ay olarak belirlenmiştir. Benzer sonuçlar 1972, 1973 ve 1993 yıllarda da meydana gelmiştir. Topçu (2013), çalışmasında Standart yağış indeksi ile kuraklığ 1973 yılında, Fidan (2011), çalışmasında 2006 yılında, Gümüş ve Algan (2017), 1970 yılında ve Sağlamoğlu (2016), ise kurak yıl olarak 1984 yılını belirlemişlerdir.

Adana'ya 1968, 1981 ve 1994 yıllarında uzun yıllar yağıș ortalaması olan 645.5 mm'nin iki katına yakın yağış düşmüştür. Adana için 1968 yılı 1264.6 mm ile yağışın en fazla olduğu yıl olmakla birlikte, 1968 yılını aylık olarak incelediğimiz zaman 5 ayın yağışlı ve 1 ayın ise kurak ay olduğu belirlenmiştir. 20082018 yılları arasında 3'er yıl kurak ve yağışlı olarak belirlenmiştir. Kurak geçen 2008 ve 2017 yılından sonra yağışlı geçen 2009 ve 2018 yılları, yağışlı geçen 2012 y1lından sonra da kurak geçen 2013 yllı Çizelge 4'de belirlenmiştir.

Yıllık toplam yağış miktarları göz önüne alındığında 1982 yılının ise 3 ay yağışlı ve 2 ay kurak ay olmasına rağmen kurak bir yıl olduğu belirlenmiştir. Bu durumun y1l içerisinde oluşan yağışların uzun yıllık aylık ortalamalardan düşük olmasına bağlı olduğu söylenebilir. Normal olarak sinıflandırılan bir yılda o yıl için bütün ayların normal ay olması beklenmemelidir. Fakat Adana ili için 2003 yılında hiç bir ayın yağışlı ve kurak ay olmamas1 dikkat edilmesi gereken bir durumdur. Normal bir yılda ay dağılımları içinde yağışlı ve kurak ayların olabileceği Çizelge 4'ten görülebilir. Aynı durumda kurak geçen bir yıl için tüm aylar kurak geçecek diye bir durum söz konusu değildir. Kurak geçen bir yılda yağışılı ay sayısı kurak ay sayısından daha fazla olabilir. Yıllık toplam yağış miktarına göre 1991 yılı yağışlı olmasına rağmen yıl içinde 2 adet kurak ay mevcut iken sadece 1 ay yağışlı geçmiştir. Bu nedenle tarımsal kuraklık çalışmalarında aylık güvenilir yağış değerleri yerine yıllık güvenilir yağış değerlerini kullanmak daha iyi bir yaklaşımdır. Elde edilen sonuçlara göre güvenilir yağış değerleri belirlenirken hangi döneme ait güvenilir yağış değerleri gerekli ise, yağışın o dönemdeki (aylık veya yıllık) geçmiş yıllara ilişkin değerleri analiz edilmelidir (Mengü ve ark. 2007). Çizelge 5'de mevsimsel olarak meydana gelen normal, yağışl1, kurak dönemler verilmiştir. İncelenen 1960-2018 y1lları arasında Kış mevsiminde 12 yıl kurak ve 10 yıl yağışlı, Sonbahar mevsiminde 9 yıl kurak ve 12 yıl yağışli, İlkbahar mevsiminde 10 yıl kurak, 7 yıl yağış̧ı ve Yaz mevsiminde ise 6 yıl kurak, 18 yıl yağışlı mevsim olarak tespit edilmiştir. Çelik ve Karabulut (2017), mevsimsel olarak hesap etmişler ve ilkbahar'da 2004, 2006, 2008 ve 2014 yıllarında, yaz aylarında 2000, 2003, 2004 ve 2010 yıllarında, kış mevsiminde 2001, 2005,2008 ve 2014 y1llarında, sonbaharda ise 2002, 2003, 2010, 2011 ve 2013 yıllarında meydana geldiğini belirlemişlerdir.

\section{Sonuç}

Adana`da en yüksek yağış miktarı 1960-2018 yılları arasında $1264.6 \mathrm{~mm}$, en düşük yağış miktarı $316.8 \mathrm{~mm}$, ortalama yağış miktarı ise $663.4 \mathrm{~mm}$ olarak bulunmuştur. Adana'da 59 yıllık süreçte 14 yıl yağışlı, 14 yıl ise kurak geçmiştir. Yağışlı bir yılda $804.8 \mathrm{~mm}$ ve üstünde yağış, kurak bir yılda ise $492.6 \mathrm{~mm}$ ve altında yağış beklenmektedir. Kurak geçen bir yılın bazı ayları yağışı bazı ayları kurak geçebilmektedir. Aynı durum yağışlı yıllar için de geçerlidir. Bu nedenle y1llık güvenilir yağış değerlerinin bulunabilmesi için aylık güvenilir yağış değerlerinin toplamı alınmamalı doğrudan yıllık toplam yağışların analizi yapılmalıdır. $\mathrm{Bu}$ durumda sulama programlaması yapılırken aylık güvenilir yağış değerleri yerine yıllık güvenilir yağış değerlerinin kullanılmasının uygun olacağı düşünülmelidir.

Adana da sulama zamanı genel olarak yaz aylarında olduğu için bu aylardaki kurak ve yağışlı aylarda düşmesi beklenen yağış miktarları göz önüne alınmalıdır. Bu bağlamda Adana'da özellikle haziran-ağustos aylarında kurak ve normal yıllarda gerçekleşmesi beklenen yağış değerleri çok az olduğu için, bu aylarda düşen yağışların sulama zamanın planlanmasında önemli olmadığı sonucuna varabiliriz. Akçay ve ark. (2007), Aydın yöresinde yaptıkları çalışmada sulamaların özellikle yaz aylarında yapıldığını belirterek bu dönemlerde kurak ve normal yıllarda gerçekleşmesi beklenen yağış miktarlarının çok düşük olması nedeni ile bu dönemler de düşen yağışların sulama zamanının planlanmasında önemli olmadığı sonucuna varmışlardır. Yapılan diğer çalışmalarda (Mengü ve ark. 2007; Yıldırım 2002) sulama programlarında yıllık, haftalık veya on günlük dönemlerin dikkate alınmasını önermişlerdir. 
Çizelge 3. Kurak, normal ve yağışlı ay durumları.

Table 3. Dry, normal and rainy month situations.

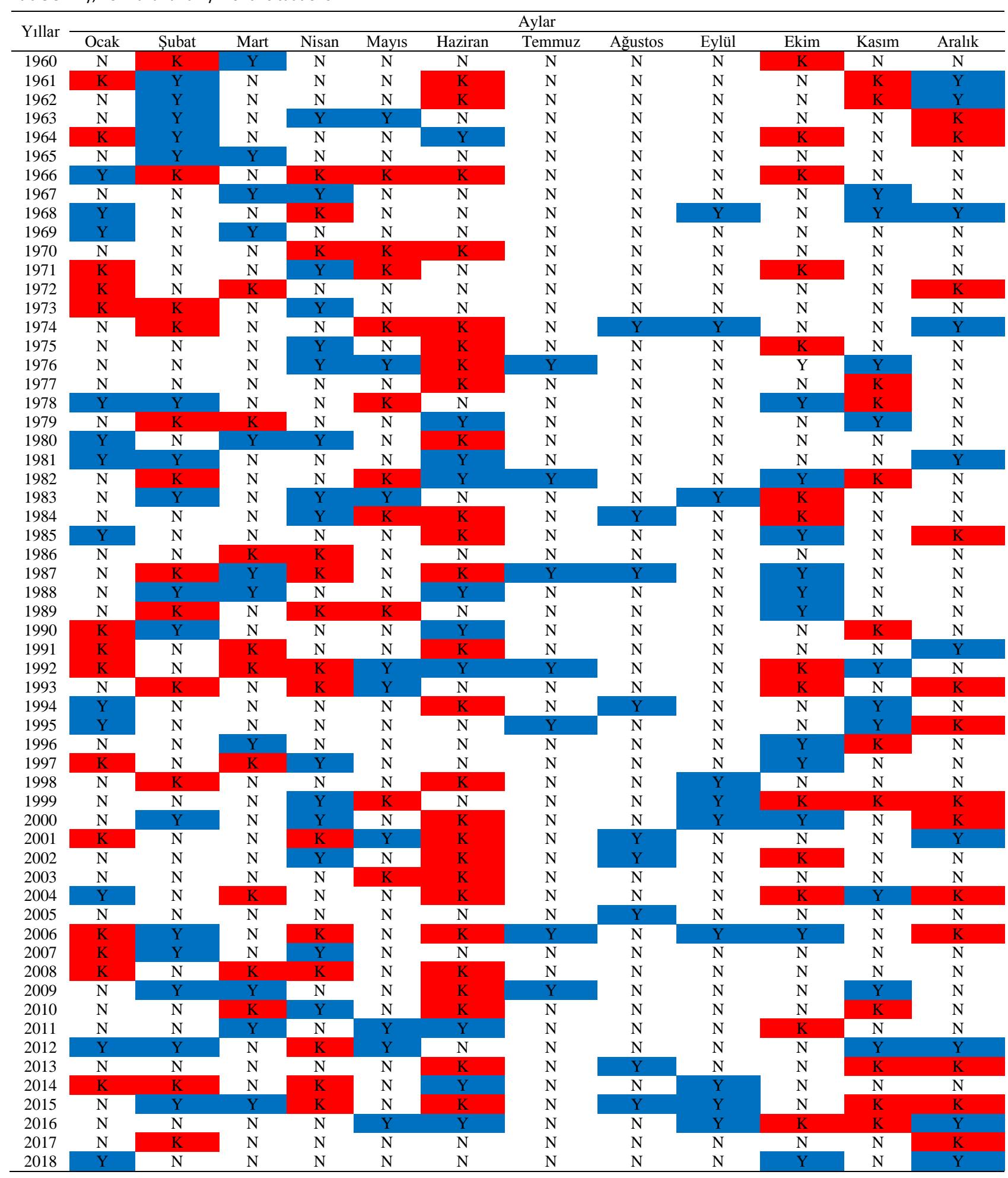


Çizelge 4. Yıl içindeki normal, yağışlı ve kurak ay sayılarının dağılımı.

Table 4. Distribution of normal, rainy and dry months in the year.

\begin{tabular}{|c|c|c|c|c|c|c|c|c|c|c|c|}
\hline \multirow[b]{2}{*}{ Yillar } & \multicolumn{4}{|c|}{ Adana } & \multirow{2}{*}{$\begin{array}{c}\text { Yillık } \\
\text { Toplam } \\
\text { Yağış }\end{array}$} & \multirow[b]{2}{*}{ Yillar } & \multicolumn{4}{|c|}{ Adana } & \multirow{2}{*}{$\begin{array}{c}\text { Yıllık } \\
\text { Toplam } \\
\text { Yağış }\end{array}$} \\
\hline & $\begin{array}{c}\text { Yıllık Yağış } \\
\text { Sınıfı }\end{array}$ & Yağışlı Ay & Kurak Ay & Normal Ay & & & $\begin{array}{c}\text { Yıllık Yağış } \\
\text { Sınıfı }\end{array}$ & Yağışlı Ay & Kurak Ay & Normal Ay & \\
\hline 1960 & $\mathrm{~K}$ & 1 & 2 & 9 & 482.2 & 1990 & $\mathrm{~K}$ & 2 & 2 & 8 & 474.7 \\
\hline 1961 & Y & 2 & 2 & 8 & 847.9 & 1991 & Y & 1 & 2 & 9 & 807.9 \\
\hline 1962 & $\mathrm{~N}$ & 2 & 2 & 8 & 666.8 & 1992 & $\mathrm{~N}$ & 5 & 4 & 3 & 705.8 \\
\hline 1963 & Y & 4 & 1 & 7 & 809.3 & 1993 & $\mathrm{~K}$ & 1 & 3 & 8 & 407.4 \\
\hline 1964 & $\mathrm{~N}$ & 3 & 3 & 6 & 530.6 & 1994 & Y & 3 & 0 & 9 & 1072.5 \\
\hline 1965 & $\mathrm{~N}$ & 2 & 0 & 10 & 666.6 & 1995 & $\mathrm{~N}$ & 4 & 1 & 7 & 727.1 \\
\hline 1966 & $\mathrm{~N}$ & 2 & 3 & 7 & 731.3 & 1996 & $\mathrm{~N}$ & 2 & 1 & 9 & 682.4 \\
\hline 1967 & $\mathrm{Y}$ & 3 & 0 & 9 & 879.2 & 1997 & $\mathrm{~N}$ & 2 & 2 & 8 & 654.8 \\
\hline 1968 & Y & 5 & 1 & 6 & 1264.6 & 1998 & $\mathrm{~N}$ & 2 & 1 & 9 & 590.8 \\
\hline 1969 & $\mathrm{~N}$ & 2 & 0 & 10 & 700.2 & 1999 & $\mathrm{~K}$ & 2 & 4 & 6 & 458.3 \\
\hline 1970 & K & 0 & 1 & 11 & 465.3 & 2000 & $\mathrm{~N}$ & 3 & 1 & 8 & 646.6 \\
\hline 1971 & K & 1 & 3 & 8 & 438.4 & 2001 & $\mathrm{~N}$ & 4 & 2 & 6 & 756.9 \\
\hline 1972 & K & 0 & 3 & 9 & 319.4 & 2002 & K & 2 & 1 & 9 & 478.2 \\
\hline 1973 & K & 1 & 2 & 9 & 407.8 & 2003 & $\mathrm{~N}$ & 0 & 0 & 12 & 587.9 \\
\hline 1974 & $\mathrm{~N}$ & 3 & 2 & 7 & 724.2 & 2004 & $\mathrm{~N}$ & 2 & 3 & 7 & 599.9 \\
\hline 1975 & $\mathrm{~N}$ & 1 & 1 & 10 & 591 & 2005 & $\mathrm{~N}$ & 1 & 0 & 11 & 524.7 \\
\hline 1976 & Y & 5 & 0 & 7 & 1041.9 & 2006 & $\mathrm{~N}$ & 3 & 3 & 6 & 574.2 \\
\hline 1977 & $\mathrm{~N}$ & 1 & 1 & 10 & 605.7 & 2007 & $\mathrm{~N}$ & 1 & 1 & 10 & 637.3 \\
\hline 1978 & $\mathrm{~N}$ & 3 & 2 & 7 & 755.2 & 2008 & K & 0 & 4 & 8 & 316.8 \\
\hline 1979 & $\mathrm{~N}$ & 2 & 2 & 8 & 546.2 & 2009 & Y & 4 & 1 & 7 & 807.6 \\
\hline 1980 & $\mathrm{~N}$ & 3 & 0 & 9 & 771.1 & 2010 & $\mathrm{~N}$ & 1 & 3 & 8 & 571.3 \\
\hline 1981 & Y & 4 & 0 & 8 & 1176.2 & 2011 & $\mathrm{~N}$ & 3 & 0 & 9 & 719.6 \\
\hline 1982 & K & 3 & 2 & 7 & 442.7 & 2012 & $\mathrm{Y}$ & 4 & 1 & 7 & 1065.4 \\
\hline 1983 & Y & 5 & 1 & 6 & 812 & 2013 & $\mathrm{~K}$ & 1 & 3 & 8 & 392 \\
\hline 1984 & $\mathrm{~N}$ & 2 & 2 & 8 & 534 & 2014 & $\mathrm{~N}$ & 2 & 3 & 7 & 593.6 \\
\hline 1985 & $\mathrm{~N}$ & 2 & 1 & 9 & 645.2 & 2015 & $\mathrm{~N}$ & 4 & 4 & 4 & 641.1 \\
\hline 1986 & K & 0 & 2 & 10 & 456.4 & 2016 & $\mathrm{~N}$ & 4 & 1 & 7 & 735.1 \\
\hline 1987 & $\mathrm{Y}$ & 5 & 2 & 5 & 906.5 & 2017 & $\mathrm{~K}$ & 0 & 2 & 10 & 458.5 \\
\hline 1988 & Y & 3 & 0 & 9 & 805.2 & 2018 & Y & 2 & 0 & 10 & 924.8 \\
\hline 1989 & $\mathrm{~N}$ & 1 & 3 & 8 & 502.5 & & & & & & \\
\hline
\end{tabular}

Çizelge 5. Mevsimlerde normal, yağışlı ve kurak dağılımı.

Table 5. Normal, rainy and dry distribution in seasons.

\begin{tabular}{|c|c|c|c|c|c|c|c|c|c|}
\hline Yillar & $\mathrm{K}_{1 S ̧}$ & Sonbahar & İlkbahar & Yaz & Yillar & Kış & Sonbahar & İlkbahar & Yaz \\
\hline 1960 & $\mathrm{~K}$ & $\mathrm{~N}$ & $\mathrm{Y}$ & $\mathrm{N}$ & 1990 & $\mathrm{Y}$ & $\mathrm{N}$ & $\mathrm{N}$ & $\mathrm{K}$ \\
\hline 1961 & $\mathrm{Y}$ & $\mathrm{N}$ & $\mathrm{N}$ & K & 1991 & $\mathrm{~N}$ & Y & $\mathrm{N}$ & Y \\
\hline 1962 & Y & K & $\mathrm{N}$ & K & 1992 & K & $\mathrm{N}$ & $\mathrm{N}$ & $\mathrm{N}$ \\
\hline 1963 & $\mathrm{~N}$ & K & $\mathrm{N}$ & $\mathrm{N}$ & 1993 & Y & $\mathrm{Y}$ & $\mathrm{N}$ & Y \\
\hline 1964 & K & $\mathrm{N}$ & $\mathrm{N}$ & Y & 1994 & $\mathrm{~N}$ & Y & $\mathrm{N}$ & Y \\
\hline 1965 & $\mathrm{~N}$ & K & $\mathrm{N}$ & $\mathrm{N}$ & 1995 & $\mathrm{~N}$ & $\mathrm{~N}$ & $\mathrm{~N}$ & $\mathrm{~N}$ \\
\hline 1966 & Y & $\mathrm{N}$ & $\mathrm{N}$ & $\mathrm{N}$ & 1996 & $\mathrm{~N}$ & Y & $\mathrm{N}$ & $\mathrm{N}$ \\
\hline 1967 & $\mathrm{~N}$ & $\mathrm{~N}$ & Y & $\mathrm{N}$ & 1997 & $\mathrm{~N}$ & $\mathrm{~N}$ & $\mathrm{~N}$ & $\mathrm{~N}$ \\
\hline 1968 & Y & Y & $\mathrm{N}$ & $\mathrm{N}$ & 1998 & $\mathrm{~N}$ & $\mathrm{~N}$ & $\mathrm{~N}$ & $\mathrm{~N}$ \\
\hline 1969 & $\mathrm{~N}$ & $\mathrm{~N}$ & $\mathrm{~N}$ & $\mathrm{~N}$ & 1999 & $\mathrm{~N}$ & Y & $\mathrm{N}$ & K \\
\hline 1970 & $\mathrm{~N}$ & $\mathrm{~N}$ & K & $\mathrm{N}$ & 2000 & $\mathrm{~N}$ & $\mathrm{~N}$ & $\mathrm{~N}$ & $\mathrm{Y}$ \\
\hline 1971 & K & $\mathrm{N}$ & $\mathrm{N}$ & $\mathrm{N}$ & 2001 & $\mathrm{~N}$ & K & $\mathrm{N}$ & Y \\
\hline 1972 & K & $\mathrm{N}$ & $\mathrm{N}$ & $\mathrm{N}$ & 2002 & $\mathrm{~N}$ & K & $\mathrm{N}$ & $\mathrm{N}$ \\
\hline 1973 & K & $\mathrm{N}$ & $\mathrm{N}$ & $\mathrm{N}$ & 2003 & $\mathrm{~N}$ & $\mathrm{~N}$ & K & K \\
\hline 1974 & $\mathrm{~N}$ & $\mathrm{~N}$ & $\mathrm{~N}$ & $\mathrm{~N}$ & 2004 & $\mathrm{~N}$ & $\mathrm{~N}$ & $\mathrm{~N}$ & $Y$ \\
\hline 1975 & $\mathrm{~N}$ & $\mathrm{~N}$ & $\mathrm{~N}$ & $\mathrm{~N}$ & 2005 & $\mathrm{~K}$ & Y & K & Y \\
\hline 1976 & $\mathrm{~N}$ & Y & Y & Y & 2006 & $\mathrm{~N}$ & $\mathrm{~N}$ & $\mathrm{~N}$ & $\mathrm{~N}$ \\
\hline 1977 & $\mathrm{~N}$ & K & $\mathrm{N}$ & $\mathrm{N}$ & 2007 & K & $\mathrm{N}$ & K & $\mathrm{N}$ \\
\hline 1978 & Y & $\mathrm{N}$ & $\mathrm{N}$ & $\mathrm{N}$ & 2008 & $\mathrm{~N}$ & $\mathrm{~N}$ & $\mathrm{~N}$ & $\mathrm{~N}$ \\
\hline 1979 & $\mathrm{~N}$ & $\mathrm{~N}$ & K & $\mathrm{N}$ & 2009 & $\mathrm{~N}$ & $\mathrm{~K}$ & $\mathrm{~N}$ & K \\
\hline 1980 & $\mathrm{~N}$ & $\mathrm{~N}$ & $\mathrm{~N}$ & $\mathrm{~N}$ & 2010 & $\mathrm{~N}$ & K & Y & $\mathrm{Y}$ \\
\hline 1981 & Y & $\mathrm{N}$ & $\mathrm{N}$ & Y & 2011 & Y & $\mathrm{N}$ & $\mathrm{N}$ & Y \\
\hline 1982 & K & $\mathrm{N}$ & K & Y & 2012 & $\mathrm{~K}$ & $\mathrm{~N}$ & $\mathrm{~N}$ & $\mathrm{~N}$ \\
\hline 1983 & $\mathrm{~N}$ & $\mathrm{~N}$ & Y & $\mathrm{N}$ & 2013 & K & Y & K & Y \\
\hline 1984 & $\mathrm{~N}$ & $\mathrm{~N}$ & $\mathrm{~N}$ & $\mathrm{~N}$ & 2014 & $\mathrm{~N}$ & $\mathrm{~N}$ & $\mathrm{~N}$ & $\mathrm{~N}$ \\
\hline 1985 & $\mathrm{~N}$ & Y & $\mathrm{N}$ & $\mathrm{N}$ & 2015 & $\mathrm{~N}$ & K & $\mathrm{N}$ & Y \\
\hline 1986 & $\mathrm{~N}$ & $\mathrm{~N}$ & K & $\mathrm{N}$ & 2016 & K & $\mathrm{N}$ & $\mathrm{N}$ & $\mathrm{N}$ \\
\hline 1987 & $\mathrm{~N}$ & $\mathrm{~N}$ & $\mathrm{Y}$ & Y & 2017 & Y & $\mathrm{N}$ & K & $\mathrm{N}$ \\
\hline 1988 & $\mathrm{~N}$ & Y & $\mathrm{Y}$ & Y & 2018 & Y & Y & K & Y \\
\hline 1989 & $\mathrm{~N}$ & Y & $\mathrm{K}$ & $\mathrm{N}$ & & & & & \\
\hline
\end{tabular}




\section{Kaynaklar}

Akçay S, Ulu MA, Gürgülü H (2007) Aydın yöresinde sulama yönünden kuraklık analizi. Ege Üniversitesi Ziraat Fakültesi Dergisi 44(1): 137-147.

Çelik MA, Karabulut M (2017) Uydu ve istasyon tabanlı kuraklık indeksleri kullanılarak Akdeniz bölgesinde kuraklık analizi (20002014). Akademik Sosyal Araştırmalar Dergisi, Yı1: 5, 44: 341-370.

Fidan HI (2011) Doğu Akdeniz bölgesinde standardize yağış indeksi (syi) ile kuraklık analizi ve markov zinciri yöntemini kullanarak kurak olma olasılıklarının belirlenmesi. Yüksek Lisans Tezi, Çukurova Üniversitesi Fen Bilimleri Enstitüsü.

Gümüş V, Algin HM (2017) Meteorological and hydrological drought analysis of the Seyhan-Ceyhan river basins, Turkey. Meteorology Application 24: 62-73.

Haque MA (2005) Estimating monthly and yearly dependable rainfall for different climatic zones of the world. Songklanakarin Journal Science Technology 27(3): 667-673.

Kodal S, Tokgöz MA, Olgun M, Öztürk F, Selenay MF, Beyribey M (1992) Yağış, toprak ve bitki desenin sulama suyu miktarı ile sistem kapasitesine etkisi. IV Ulusal Tarımsal Yapılar ve Sulama Kongresi, s. 15-25.

Kodal S, Yıldırım YE, Sönmez FK (2003) Türkiye'de güvenilir yağışın mekansal dağılımı. Tarım Bilimleri Dergisi 9(4): 421-427.
Mengü GP, Akkuzu E, Akçay S (2007) Küçük menderes ovasında sulama açısından güvenilir yağış analizi. Adnan Menderes Üniversitesi Ziraat Fakültesi Dergisi 4(1-2): 15-20.

Raes D, Song Z, Mallants D, Wyseure G (1989) RAINBOW, Frequency analysis and probability plotting of hydrologic data test of homogeneity of hydrologic records, reference manuel. Katholieke Universite at Leuven, Center for Irrigation Engineering, Belgium.

Raes D, Willems P, Gbaguidi F (2006) RAINBOW a software package for hydrometeorological frequency analysis and testing the homogeneity of historical data sets. Proceedings of the 4 International Workshop on "Sustainable Management of Marginal Drylands", Islamabad, Pakistan, pp. 27-31.

Sağlamoğlu A (2016) Doğu Akdeniz bölgesinde yağışların trend ve kurak dönem analizleri. Yüksek Lisans Tezi, Mustafa Kemal Üniversitesi Fen Bilimleri Enstitüsü.

Smith M (1992) CROPWAT- A computer program for irrigation planning and management. FAO Irrigation and Drainage Publications, No. 46, Rome.

Topçu E (2013) L-momentler ve standart yağış indeksi (syi) yardımıyla seyhan havzası kuraklık analizi. Yüksek Lisans Tezi, Çukurova Üniversitesi Fen Bilimleri Enstitüsü.

Yıldırım YE (2002) Salihli yöresinde sulama açısından kuraklık analizi. Ege Üniversitesi Ziraat Fakültesi Dergisi 39(3): 112-119. 